International Journal of Industrial Engineering Research and Development (IJIERD)

Volume 6, Issue 2, July-Dec 2015, pp. 19-23, Article ID: IJIERD_06_02_003

Available online at https://iaeme.com/Home/issue/IJIERD?Volume $=6 \&$ Issue $=2$

ISSN Print: 0976 - 6979 and ISSN Online: 0976 - 6987

DOI: https://doi.org/10.34218/IJIERD.6.2.2015.003

(C) IAEME Publication

\title{
EFFECT EVALUATION IN ENGINEERING PROGRAM
}

\author{
Dr. A. Gayathiri, Dr. A. Balasubramanian and Dr. P. Sakthiselvan \\ Asst. Professor, Petroleum Engineering, AMET University, India
}

\begin{abstract}
This paper portrays the foundation, amendment and appraisal process for instructive results of substance and petroleum building projects. This procedure is started by characterizing the Chemical and Petroleum programs results to coordinate the $A B E T(A-K)$ EC2000 criteria since project results are the most critical piece of the instructive procedure and must cultivate achievement of system instructive destinations. At that point a mixed bag of immediate and circuitous appraisal apparatuses are proposed to decide how well moves on from both building projects are meeting the set up results. Three direct devices are executed in the evaluation process, to be specific; courseleducational programs appraisal, exit exam and capstone courses. The proposed circuitous devices incorporate temporary position consultant study, course evaluation by understudies, graduated class study, boss overview, understudies post employment survey, and modern counselling board. A calendar for gathering the appraisal information to bolster the survey of project goals, results, and educational programs is suggested. The general appraisal of accomplishment of system results is performed by averaging the proposed appraisal instruments utilizing a weighting variable intended to give some judgment on the significance, quality, and number of inputs of every instrument. Projects points of interest and the evaluation's after effects process for one cycle are exhibited in this paper.
\end{abstract}

Keywords: ABET, chemical and petroleum programs.

Cite this Article: Dr. A. Gayathiri, Dr. A. Balasubramanian and Dr. P. Sakthiselvan. Effect Evaluation in Engineering Program, International Journal of Industrial Engineering Research and Development, 6(2), 2015, pp. 19-23.

https://iaeme.com/Home/issue/IJIERD?Volume $=6 \&$ Issue $=2$

\section{INTRODUCTION}

The compound and petroleum designing division at the United Arab Emirates University was set up in 1980. The Chemical's mission and Petroleum Engineering projects is to meet the instructive, research, and administration needs of UAE society by giving projects and administrations of the most noteworthy quality. Likewise it 
adds to the development of information by leading quality examination and by creating and applying present day building apparatuses and methods that could assume a critical part in the specialized and monetary improvement of the nation.

The targets of ABET accreditation are to serve general society, industry, and the calling by animating the advancement of enhanced building instruction, empowering new and imaginative ways to deal with designing instruction, and guaranteeing that alumni of a licensed project are sufficiently arranged to enter and proceed with the act of designing. The new created criteria of ABET for certifying designing projects EC 2000 (A-K) have changed the way that building projects set up their graduates (Bai and Pigott, 2004). With a specific end goal to get by later on, every system needs to build up a methodology to meet the new prerequisites indicated in the EC2000 (A-K).

The Department of Chemical and Petroleum Engineering has set up an all around characterized process for results appraisal for the Chemical and Petroleum Engineering programs with a specific end goal to guarantee that their graduates accomplish the project instructive targets. Three direct devices are actualized in the evaluation process, to be specific; course/educational modules appraisal, exit exam, and capstone courses. The proposed roundabout devices incorporate temporary job counsel overview, course appraisal by understudies, graduated class study, manager study, understudies post employment survey, and modern consultative board. This paper intends to portray the foundation, update and appraisal process for instructive results of concoction and petroleum designing projects.

\section{PROGRAM OUTCOMES}

The College of Engineering at UAEU was introduced in September 1980 with two scholastic offices; the Civil Engineering Department and the Chemical and Petroleum Engineering Office. The Chemical and Petroleum Engineering office kept on offering a joint degree in Chemical and Petroleum Engineering until 1988, and from that point forward discrete degrees in Concoction Engineering and Petroleum Engineering have been advertised. Amid that period, significant equivalencies to ABET certify Chemical and Petroleum Engineering projects was allowed twice. The projects are currently under another survey by ABET and it is trusted that it will be allowed full accreditation.

These results are simple; they identify with the aptitudes, information, and practices that understudies get in their registration through the CHME and PETE programs. They too portray what understudies are relied upon to know and have the capacity to do when of graduation. The office surveys its results at regular intervals in view of changes in ABET criteria and input gotten from constituents.

\section{CHME AND PETE PROGRAM OUTCOMES ASSESSMENT}

\subsection{Achievement of Program Outcomes}

The Department of Chemical and Petroleum Engineering has set up an all that much portrayed procedure for results assessment for the Chemical and Petroleum Engineering Programs to ensure that its graduates fulfill the venture informative objectives. It demonstrates the proposed framework for the program's establishment targets and results examination process. The gigantic component of this suggestion is appeared by the two circles making up the assessment process.

The bodies electorate (graduated class, organizations and work force) give the objectives' information to the extent diagrams and direct contact in Open House social 
events. The data is amassed and examined before it can be used to evaluate and review the objectives. Besides, this information is combined into the determination and alteration of the outcomes that are required to finish these objectives, as spoke to. The second circle is made out of the evaluation and appraisal of the outcomes' achievement. In light of the outcomes, the venture instructive projects, courses, and understudy activities are arranged. Data obtained from the examination activities is vital to both circles and it moreover drives the task toward change.

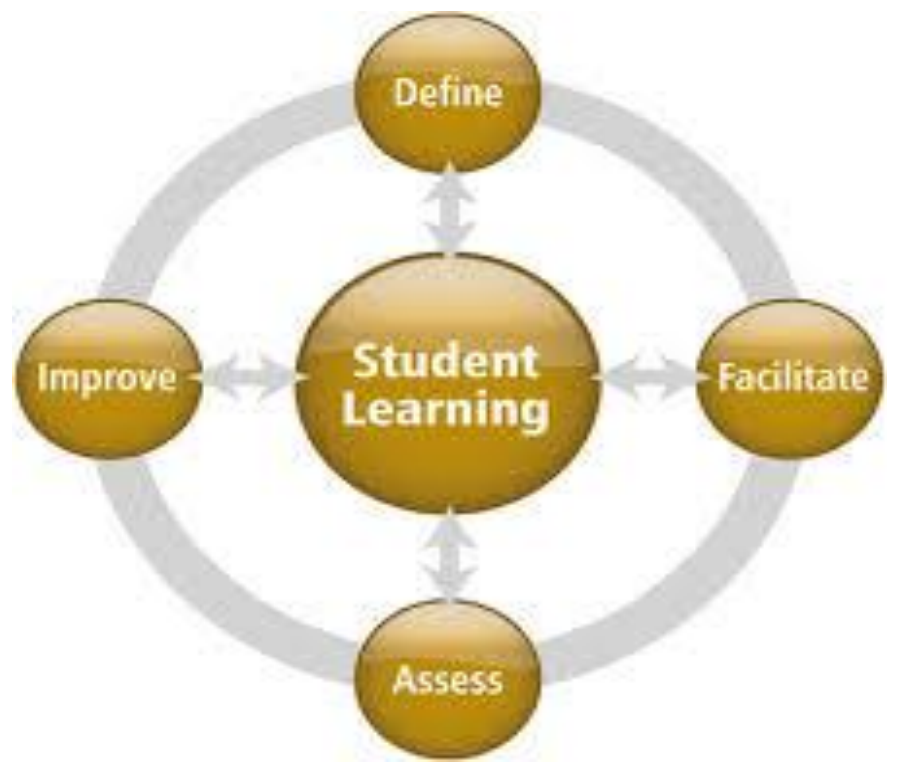

Figure 1 Framework for assessment

\subsection{Course and Curriculum Assessments}

The educational programs evaluation procedure collects singular commitments from chose courses in the CHME and PETE projects to the get program results with the end goal of evaluating the whole educational programs. By mapping the project results to the system targets, suggestions could be made toward the procedure's end to enhance the project results as well as the system instructive targets. The procedure then starts from the very beginning once more.

\subsection{Exit Exam}

A way out exam incorporating all the center courses in the Chemical and Petroleum Engineering Programs with 50 inquiries was planned keeping in mind the end goal to survey the understudies in their last semester. This exam is led amid the last divide of Graduation Project II course. Exit exam inquiries were likewise mapped to ABET criteria and evaluation of the exam is incorporated into the general evaluation.

\subsection{Capstone Course}

The capstone outline course is spread more than two semesters as Graduation Project I and Graduation Venture II. The CHME and PETE projects utilize the consequences of the GP II (majority of outline work) just in the evaluation process. It was found that understudies performed entirely well in accomplishing the project expected results.

\subsection{Internship Advisor Survey}

All CHME and PETE understudies are required to join the modern preparing project after they complete no less than 114 credit hours. Every student spends a full semester 
(around four months) in an modern setting. The mechanical director is requested that finish an overview to survey the learner's capacities, states of mind and abilities significant to the instructive results of the CHME and PETE programs.

\subsection{Alumni Survey}

The graduated class review was intended to give the data required by the CPE Department to measure the proposed results for the CHME and PETE programs. For this reason two sorts of graduated class reviews were led:

- For crisp graduates with under 3 years experience, and

- For senior graduates with three years experience or more.

\subsection{Employer Survey}

The overview was directed to evaluate how well CHME/PETE graduates meet the system result criteria as judged by their managers. This review is thought to be one of the essential criticism devices from the system voting public. The Employer Survey contains two sets of inquiries; the first set incorporates 5 addresses that fit in with the system instructive targets and the second set incorporates 11 addresses that comply with the project results. The consequences of bosses' appraisal of the CHME and PETE programs results through the execution of its graduates are accomplished by processing the weighted normal of the study to each project A-K result.

\subsection{Exit Interview}

The Exit Interview was intended to get a few remarks specifically from graduating understudies. In the meeting, graduating seniors were made inquiries that attention on their conclusions with respect to their involvement with UAEU and their view of accomplishing the CHME and PETE programs results (as reflected by the ABET results). The aftereffects of this meeting are subjective and along these lines don't have a weight in the general appraisal of the project. Be that as it may, understudies' remarks were considered in the consistent change cycle of the project.

\subsection{Overall Assessment of Achievement of Program Outcomes}

The accompanying segment compresses the appraisal's aftereffects for quantitative information assembled on a customary premise that were utilized to survey the nature of accomplishment of the results and examination of those evaluation results. The appraisal instruments weight conveyance was chosen in agreement to the level of quality of the instrument as takes after: Curriculum (30\%), Employer Survey (25\%), Temporary job (5\%), Capstone Courses (10\%), Alumni Survey (20\%), Exit Exam $(5 \%)$ and Student Evaluation of Course (5\%). The information were totaled to assess individual system results independently.

\section{PERSISTENT IMPROVEMENT}

Further change in the educational modules results appraisal can be accomplished by some mix of the accompanying; (a) usage of center gatherings proposals, (b) overhauling obviously materials, (c) acquainting new programming bundles with unravel building issues, (d) underlining collaboration, (e) moving to industry-situated outline issues in capstone courses, and (f) presenting new courses if essential. The general's consequences result appraisal for year 2008 appeared in Table 3 show that every one of the A-K program results have been met. Be that as it may, more work is by all accounts expected to enhance result $\mathrm{J}$ in synthetic designing project and results 
$\mathrm{B}$ and $\mathrm{C}$ in petroleum building system. Proposals made by center gatherings for CHME and PETE courses were mostly derived from the consequences of the different appraisal apparatuses utilized as a part of the proposed procedure of system results evaluation. These suggestions are to be actualized in the predefined courses amid the consequent semesters.

\section{CONCLUSION}

An efficient methodology is proposed in this study for the appraisal of CHME and PETE programs' instructive results. Immediate and roundabout appraisal instruments were prescribed and actualized to accomplish this reason. The aftereffects of the proposed results appraisal process can prompt ID of purposes of shortcomings and qualities in the system which could then be deciphered into activities for the change of the CHME and PETE programs. The assessment procedure created in this work for the CHME and PETE programs at UAEU is prescribed for implantation in other building orders and subdiscplines.

\section{REFERENCES}

[1] Chemical Engineering Program (CHME) Self-Study Report, United Arab Emirates University, Submitted to the Engineering Accreditation Commission Accreditation Board for Engineering and Technology, July 2009.

[2] Bai, Y., and Pigott, R. 2004. Assessing Outcomes Using Program Assessment Portfolio Approach. Journal of Professional Issues in Engineering Education and Practice, 130 (4), 246-254.

[3] Petrova, R., Tibrewal, A., Sobh, T.M. 2006. An Electronic Web-based Assessment System. Journal of STEM Education, 7 (3\&4), 44-57.

[4] Petroleum Engineering Program (PETE) Self-Study Report, United Arab Emirates University, Submitted to the Engineering Accreditation Commission Accreditation Board for Engineering and Technology, July 2009. 